\title{
FLOW CHARACTERISTICS OF AN UNCONSTRAINED, NON-COHESIVE, GRANULAR MEDIUM DOWN AN INCLINED, CURVED SURFACE: PRELIMINARY EXPERIMENTAL RESULTS
}

\author{
by
}

\author{
R.M. Lang, B.R. Leo, and K. Hutter
}

(Institut für Mechanik, Technische Hochschule Darmstadt, Hochschulstrasse 1, D-6100 Darmstadt, Federal Republic of Germany)

\section{ABSTRACT}

Some preliminary experimental results are presented, which characterize the behaviour of small-scale artificial avalanches. The laboratory simulation consisted of releasing a finite mass of non-cohesive granular material to flow without restriction down an inclined surface which includes a curved part at the base where the run-out zone is encountered. Three contrasting materials, of $3 \mathrm{~mm}$ and $5 \mathrm{~mm}$ diameter size sortings, and also two different bed roughnesses were used.

Results indicate that a theoretical model which presumes a flow-regime-type avalanche may be too restrictive, in the sense that it describes a limiting case which does not of ten occur even under controlled conditions. Some suggestions are made for amendments to current theoretical concepts.

\section{INTRODUCTION}

Recent years have witnessed an increased impetus in the study of snow and ice avalanches, rockslides, and landslides. A review of relevant literature has been written by Hutter and others (1989). Most studies deal with the mathematical formulation of model equations, their integration and, where possible, verification by means of field observations.

Physically, avalanches can be categorized as multiphase flows. At present our knowledge of these granular flows is quite unsatisfactory. It is particularly important to try to obtain a fundamental understanding of the physics involved in avalanche flow and from this to develop governing equations and closure relationships which describe them.

It is extremely difficult to make measurements on avalanches and related phenomena as they occur in Nature (Gubler, 1987), therefore laboratory simulation of avalanches is an extremely important means of developing basic theoretical concepts. Some advances in this area have recently been made (Hutter and others, 1988), but the investigations in question were restricted to two-dimensional flows in which the material is constrained in a channel. The concept of a granular fluid subject to Coulomb-like yield has proved to be a fairly adequate theoretical model in predicting the two-dimensional channel-flow laboratory experiments (Hutter and others, 1988, 1989; Savage and Hutter, 1989). For this type of situation it is assumed that the mean free path of moving particles is equivalent to the particle size. However, although this is a possible situation in Nature, it is more likely that an actual avalanche is occasionally initiated as a channel-type flow and then typically encounters a topography where it is allowed to deform, constrained only by the surface upon which it is flowing. In order to address this problem, we have completed a preliminary series of experiments in which we have investigated the behaviour of non-cohesive granular media, which have been allowed to flow freely down surfaces of varying topography. These experiments were intended in a qualitative sense to give a direction for future experiments, and an indication of what is occurring physically, in order to lay the ground work for an appropriate avalanche model in three dimensions.

\section{EXPERIMENTAL PROCEDURE}

A $2 \mathrm{~m}$ wide by $5 \mathrm{~m}$ long Makralon (Plexiglass) surface was constructed such that the top $2 \mathrm{~m} \times 2 \mathrm{~m}$ part representing the initiation zone could be inclined from $20^{\circ}$ to $60^{\circ}$ with respect to the horizontal in $5^{\circ}$ increments (Fig. 1). Changing the angle of inclination caused a change

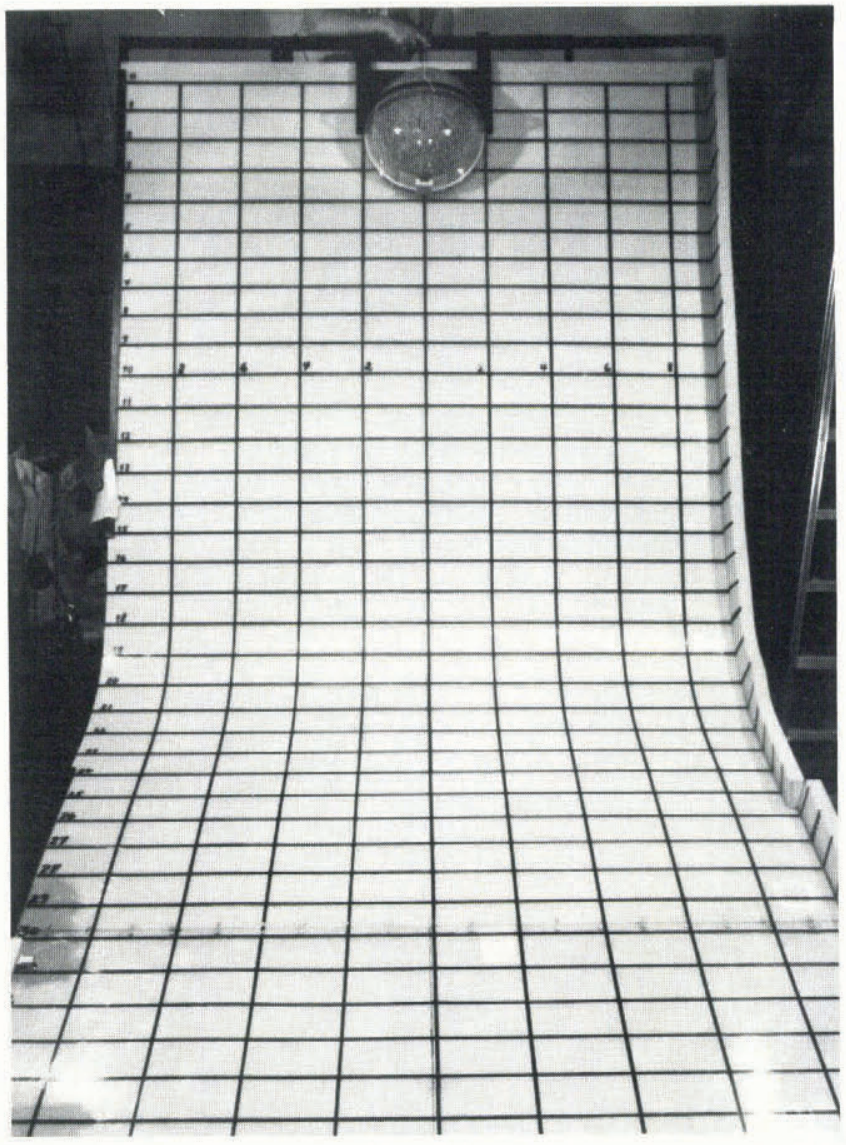

Fig. 1. Top view of experimental surface; width $=2 \mathrm{~m}$, length $=5 \mathrm{~m}$, grid spacing $=200 \mathrm{~mm} \times 100 \mathrm{~mm}$. 


\begin{tabular}{|c|c|c|c|c|c|}
\hline Material & $\begin{array}{l}\text { Particle } \\
\text { shape }\end{array}$ & $\begin{array}{l}\text { Particle-size } \\
\text { diameter }\end{array}$ & $\begin{array}{l}\text { Bulk density } \\
\text { at densest } \\
\text { packing }\end{array}$ & $\begin{array}{l}\text { Internal } \\
\left.\text { angle ( }{ }^{\circ}\right) \\
\text { of friction }\end{array}$ & Bed-friction angle $\left({ }^{\circ}\right)$ \\
\hline
\end{tabular}

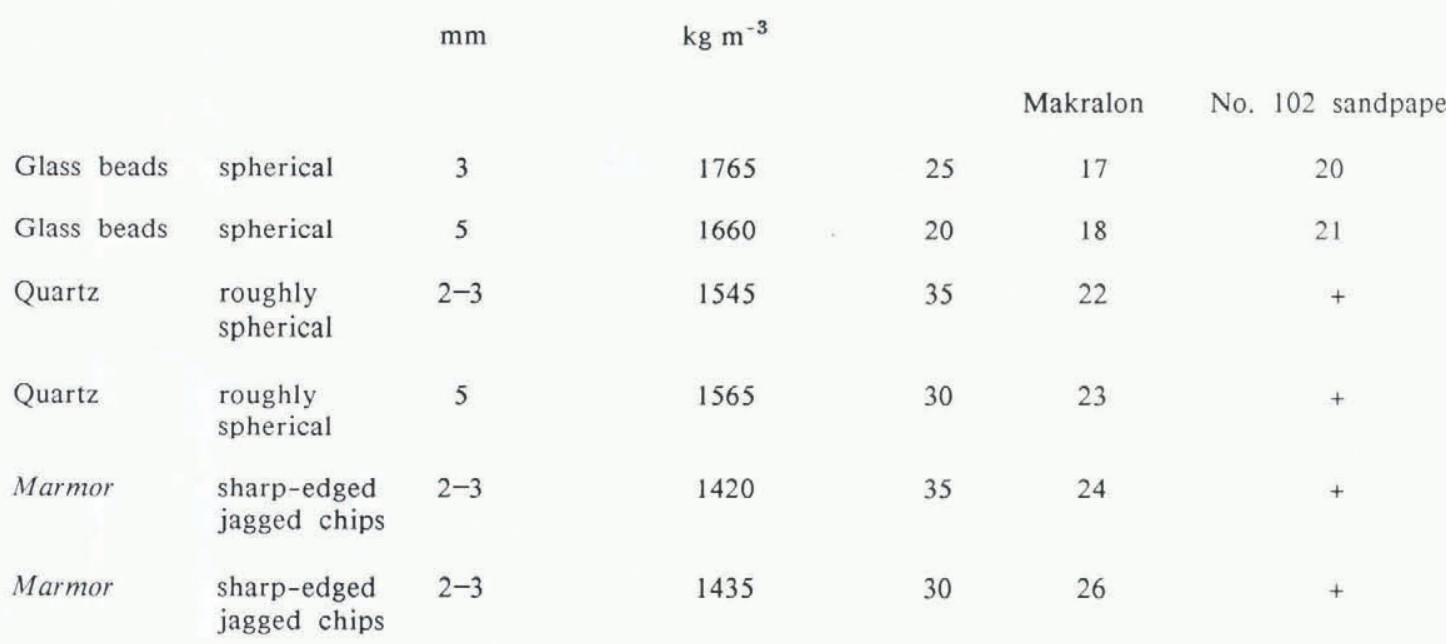

+, Unable to measure with testing device.

in the radius of curvature at the base of the initiation zone. The curved part then intersected a flat $3 \mathrm{~m}$ long run-out zone. The whole surface was divided into a grid with a network of rectangles $100 \mathrm{~mm}$ in length and $200 \mathrm{~mm}$ wide. Spherical glass beads, approximately spherical quartz particles, and angular chips of marmor (a partially metamorphosed limestone) were used as the granular media. The materials were cleaned and size-sorted into $3 \mathrm{~mm}$ and $5 \mathrm{~mm}$ diameter samples. Two distinctly different bedsurface roughnesses, the Makralon and SIA No. 120 sandpaper, were utilized. Material parameters are listed in Table I.

Two parameters characterize the cohesionless Coulombtype material: the internal angle of friction, which equals the angle of repose, and the bed friction angle. The latter was determined by placing a small annulus on a tilt-board whose surface roughness replicated the surface of the slide, filling the paper cylinder with several layers of the granular material, and then tilting the board until the angle at which the cylinder with the enclosed granulate started to slide was determined.

The artificial avalanches were created by containing the mass of the granular medium in a half sphere of prescribed volume to the densest possible packing, and releasing it by the rapid removal of the sphere, as shown in Figure 2. Some adhesion between the surface of the sphere and the particles occurred in the initial motion, but after that the granulate was then allowed to flow without constraint. The motion of the mass was recorded with a $35 \mathrm{~mm}$ motordriven camera at a rate of $10-15$ frames/s. A wide-angle lens was used in order to include the entire experimental surface in each frame.

\section{EXPERIMENTAL RESULTS}

The behaviour of all of the artificial avalanches showed some common features. The initial motion was the typical motion expected for an unconstrained flow due to gravity; the mass of suddenly released granules collapsed and flowed outward and downward in such a manner that the potential energy of the mass due solely to static or overburden pressure was converted to the kinetic energy of its motion. After this initial yield, the material dilated having previously been in a state of over-consolidation. The order of magnitude of this dilation is yet to be determined. If

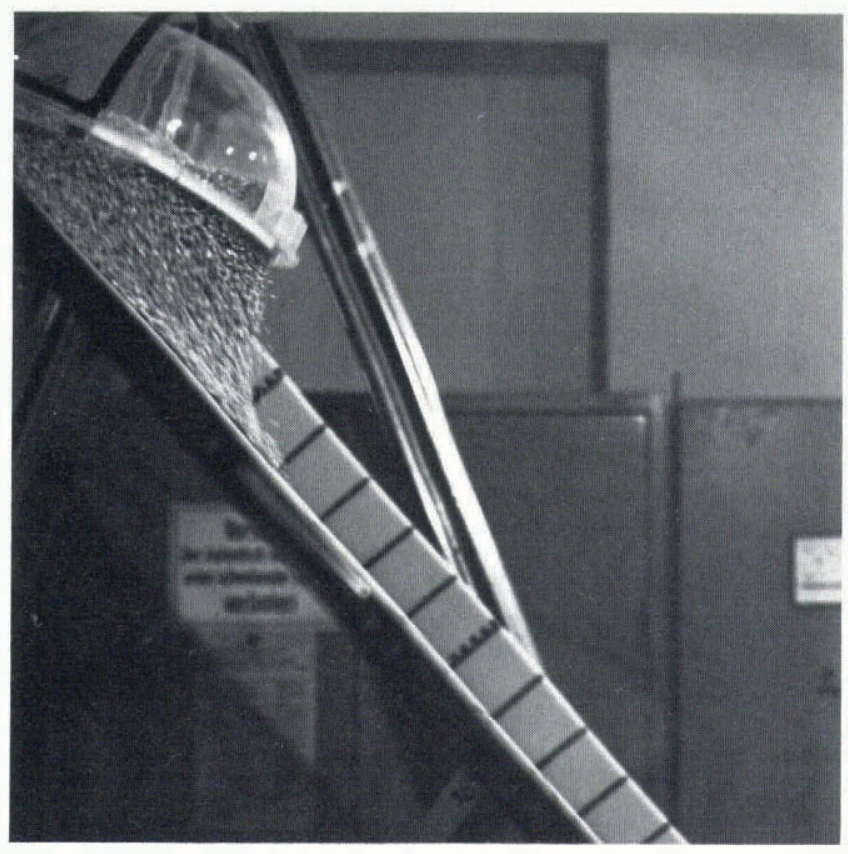

Fig. 2. Side view demonstrating release of granulate material.

the angle of inclination, $\alpha$, of the initiation zone was greater than the bed-friction angle, $\delta$, for a particular material and surface roughness, the mass continued to flow downward and outward, due both to shear failure at the surface-material interface and to loss of internal resistance. The rate of shear increased rapidly in the initial phase of motion and generated large impulsive contact pressures, the particles became randomly separated, and the mass appeared to continue to dilate. As a consequence, both bed resistance and internal resistance were correspondingly reduced. The granules attained their maximum distance of travel as the leading edge reached the transition zone or the mid-point of curvature. Movement of the lower layers was then retarded by the ground surface and this had a considerable effect on the form of the leading edge of the flowing mass. 


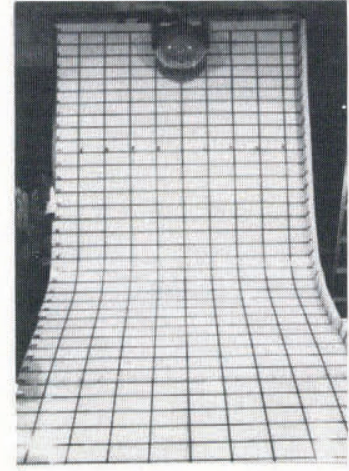

1

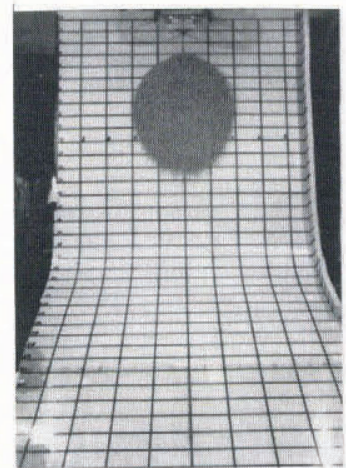

5
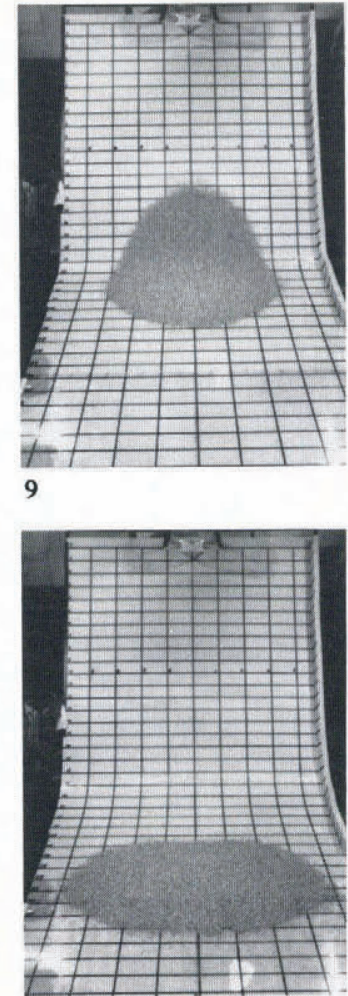

13

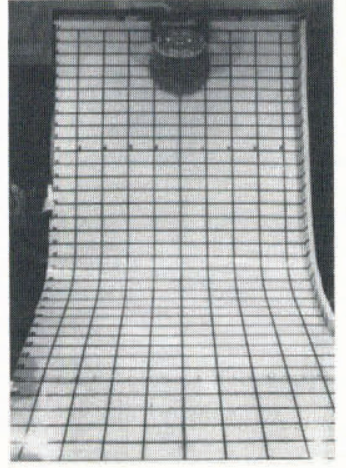

2

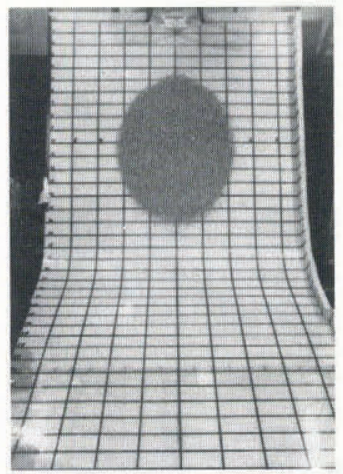

6

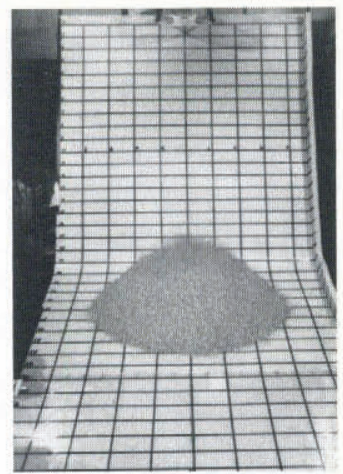

10

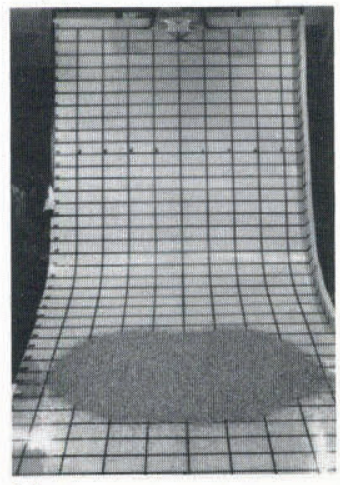

14

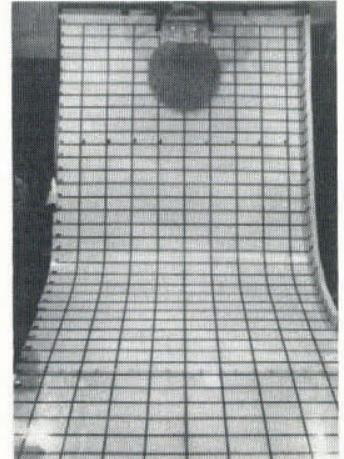

3

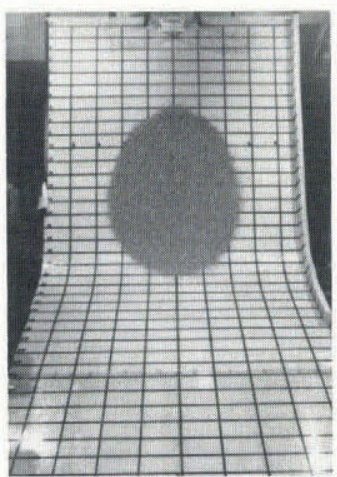

7

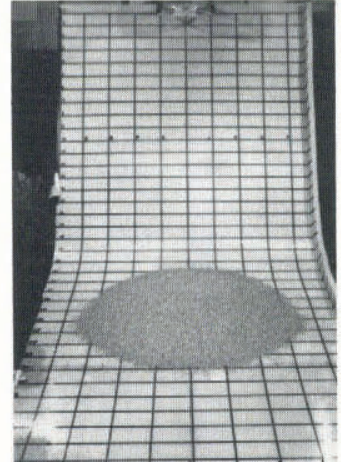

11

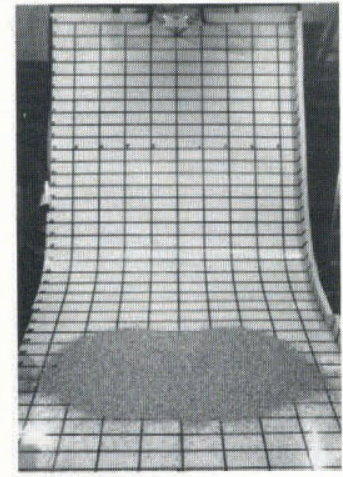

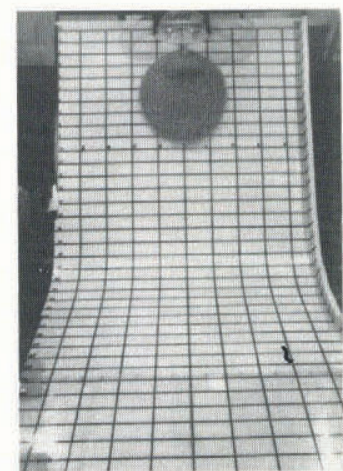
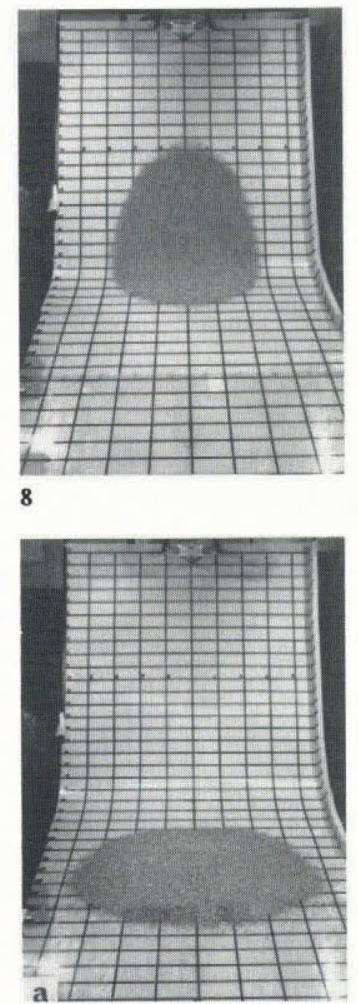

12

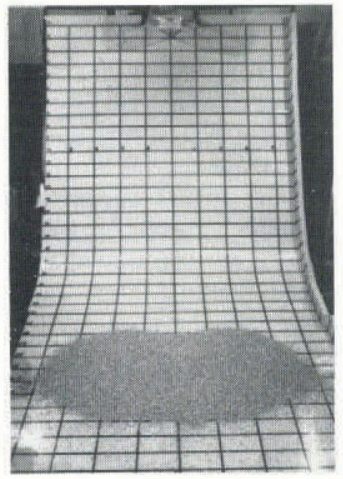

16

Fig. 3.1-16. Laboratory avalanche (No. DA 032) of $5 \mathrm{~mm}$ quartz particles; initiation zone angle $=45^{\circ}$, total mass $=20.5 \mathrm{~kg}$, time interval $=0.1 \mathrm{~s}$ per frame.

Figure $3.1-16$ depicts the motion of $20.5 \mathrm{~kg}$ of $5 \mathrm{~mm}$ quartz granules on the Makralon surface (avalanche No. DA 032) when the initiation zone was inclined at an angle of $45^{\circ}$. Figure $3.1-7$ shows how the mass was continually spreading outward and downward in the initiation zone; in Figure 3.7 the leading edge had attained its maximum velocity of $4.0 \mathrm{~m} \mathrm{~s}^{-1}$ after $0.8 \mathrm{~s}$ of flow, as it entered the transition zone. The lower layers were decelerating at the front of the mass but the tail continued to accelerate for a further $0.3 \mathrm{~s}$. The mass thickens in the curved part of the bed due to this braking action and also under the influence of the centripetal force generated by the curvature. In Figure $3.12 \mathrm{a}$ and $\mathrm{b}$ one can easily detect that the leading edge was extremely fluidized, although the lower layers had already come to rest. The final shape in the run-out zone (Fig. 3.16) appears to indicate that the tail of the flow had sufficient momentum to continue to move over the deposition pile. 


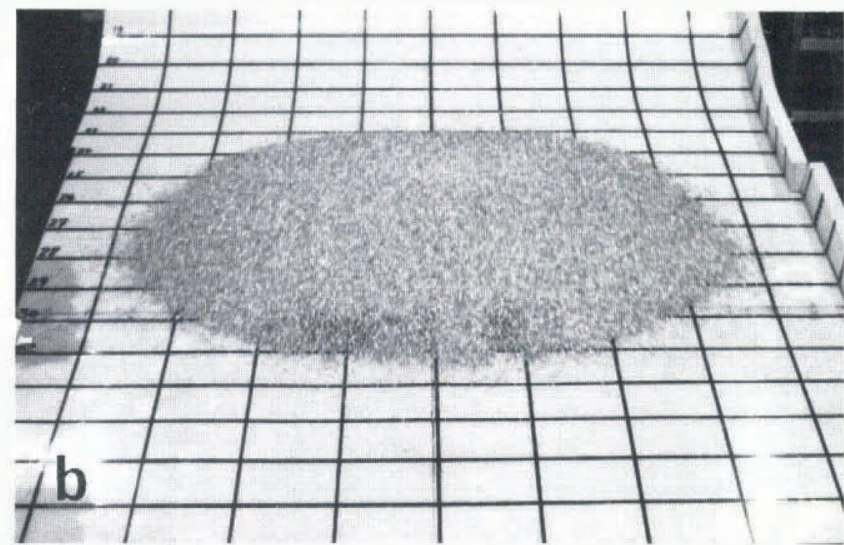

b

Fig. 3.12b. Enlargement of Figure 3.12 to demonstrate fluidization at leading edge.

Figure 4 provides a side view of the quartz avalanche (No. DA 025) as it travelled through the curved zone of the bed. The high degree of fluidization of the particulate mass is quite obvious and the contraction of the granulate resulting from thickening in the transition zone is also evident.

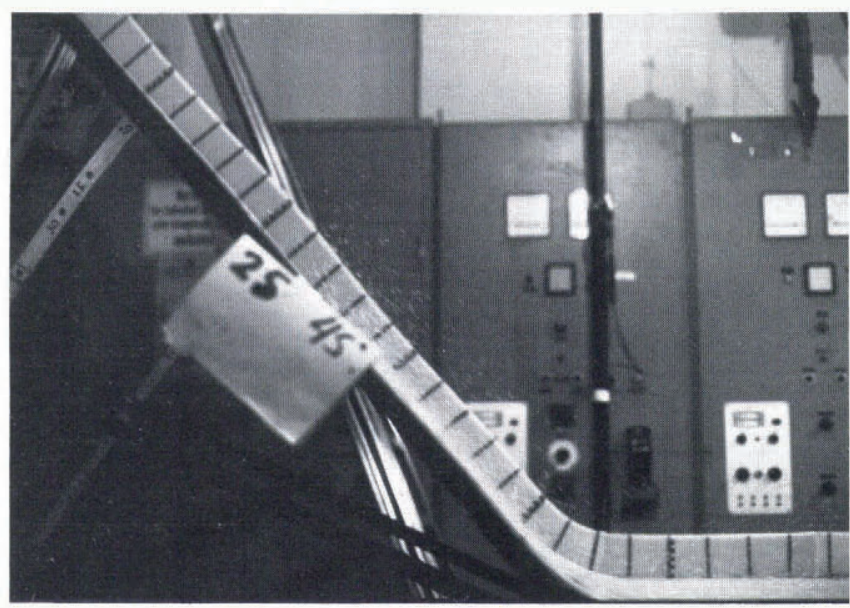

Fig. 4. Side view of $2-3 \mathrm{~mm}$ quartz particles (avalanche No. DA 025) flowing through curved part of bed. Note degree of fluidization and thickening in curvature.

Figure 5.1-16 shows an avalanche (No. DA 022) of glass beads, $5 \mathrm{~mm}$ in diameter. $21.8 \mathrm{~kg}$ of these beads were released on to a Makralon surface at an angle of $45^{\circ}$. Approximate velocity profiles for the toe and tail of the flow are depicted in Figure 6. As shown, the leading edge accelerated quite rapidly whilst the tail remained static for approximately $0.2 \mathrm{~s}$. As the tail begins to move, the motion is due to bed failure. The internal and bed friction exert retarding forces on those parts of the mass which were trying to move at higher relative speeds (i.e. the solid surfaces which were in relative motion experienced frictional forces). However, as the leading edge moved out, the shear rate increased and this in turn increased the impulsive contact pressure so that both the front and the surface of the flow continued to dilate. The internal resistance to flow was thus reduced.

If we consider the leading edge to have a thickness greater than one particle diameter, the approximate maximum velocity of $4.0 \mathrm{~m} \mathrm{~s}^{-1}$ occurred at $0.7 \mathrm{~s}$ after the onset of motion, and the avalanche attained its maximum length of $1.44 \mathrm{~m}$ at $0.8 \mathrm{~s}$ from the start of the run, as the leading edge passed through the transition zone. The tail continued to accelerate to $4.1 \mathrm{~m} \mathrm{~s}^{-1}$ for $0.2 \mathrm{~s}$ and then decelerated quite rapidly as the material contracted in the run-out zone. A single layer of particles continued to travel at high speed past the limits of the experimental surface; this may have been partly due to the degree of fluidization of the leading edge, but was certainly also due to the spherical nature and elasticity of the glass beads which facilitated the rolling and saltating of the individual particles. For this experiment, the total elapsed time was $1.7 \mathrm{~s}$. If we consider the single layer of glass beads as the leading edge, the final length and width exceeded $2 \mathrm{~m}$ and the final height was less than five particle diameters, that is less than $25 \mathrm{~mm}$. When the final length was measured, neglecting the scattered beads, it was found to be $0.7 \mathrm{~m}$. The resulting shape of the glass-bead avalanche was a wide, thin pile (Fig. 5.16) with a parabolically shaped tail.

In order to demonstrate the strong dependence of flow behaviour on the parameters of both material and the surface, Figure 7.1-16 depicts the avalanche (No. DA 051) simulated by $18.6 \mathrm{~kg}$ of marmor released at an angle of $45^{\circ}$ on a surface of sandpaper. The initial acceleration was slower, and the pile of material elongated more dramatically, than for the previously described materials. The maximum velocity of $3.0 \mathrm{~m} \mathrm{~s}^{-1}$ occurred after $0.8 \mathrm{~s}$ (Fig. 8), the maximum distance travelled after $0.9 \mathrm{~s}$ again occurred as the leading edge reached the transition zone, the tail accelerated quite slowly, and the maximum measured velocity of $3.3 \mathrm{~m} \mathrm{~s}^{-1}$ was achieved after $1.6 \mathrm{~s}$. The marmor deposition (Figs 9 and 7.16) had a maximum height of approximately $60 \mathrm{~mm}$, and was shaped somewhat like a barchan dune, with a slip front developed at the toe of the deposition. Since marmor granules did not dilate to the same extent as did glass beads, the leading edge could more easily be defined, as the layer of single particles represents a much smaller proportion of the original total volume. A deposit of powder remained on the surface and outlined the outermost edge of the marmor avalanche.

Comparison of the glass-bead and marmor avalanches (Figs 5 and 7) demonstrates the strong dependence of resulting deposition on the total mass of material, the internal resistance of the material to plastic deformation, the collisional properties of the particles, and the bed roughness.

Table II summarizes the results of our experiments. It should be noted that, because the photographic method is limited to a specific number of frames per second, the maximum velocities recorded are obviously subject to some error.

\section{THEORETICAL IMPLICATIONS AND CONCLUSIONS}

Following the work of Hutter and Savage (1988), we have extended a purely mechanical theory in curvilinear coordinates into three dimensions. The presentation of this work will be reserved for a future paper. It is, however, possible at this stage to comment on the theoretical concepts. Assumptions include incompressibility, and limiting fluidization to a small boundary layer such that its incorporation into a sliding-law expression is both possible and reasonable.

A mass-balance equation which assumes incompressibility is useful in a somewhat limited sense. Within the vertically averaged theories of Savage and Hutter (1989), it is possible to show that, for a representative depth- and widthaveraged velocity, dilatational effects can be incorporated without significantly changing the evolution equations. The incompressibility assumption of Savage and Hutter was based on descriptive field observations (Melosh, 1986) and on their own deductions from the study of confined chute flows of a finite mass of gravel (Hutter and others, 1988) and made implicit use of the fact that the basal zone would be the active zone in which nearly all shearing takes place. By qualitatively examining our experimental results, we conclude that very few of these artificial avalanches would represent a flow-type avalanche, because they show only an extreme, or limiting, case and for practical purposes we need to recognize that most situations are of an intermediate or mixed nature. This means that within any assembly of particles some are widely spaced, some are in rapid motion, and that the particle-to-particle contact is usually brief, in spite of the observation that some particles experience semi-permanent contact. These flows are accelerating flows, 


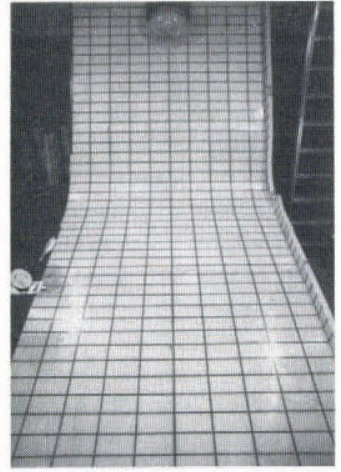

1
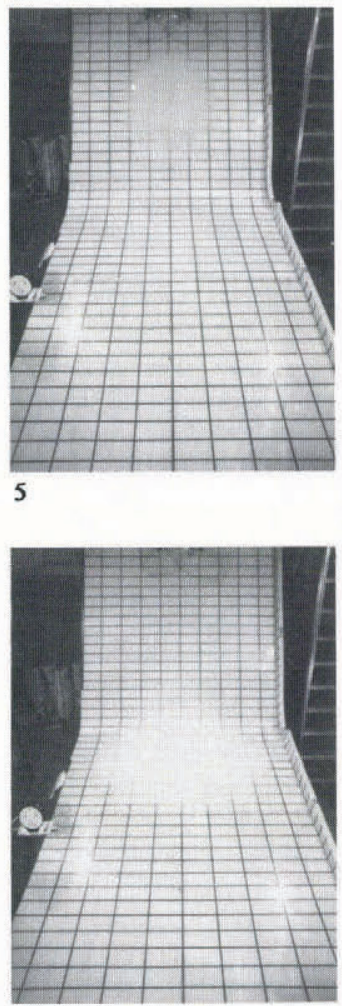

9

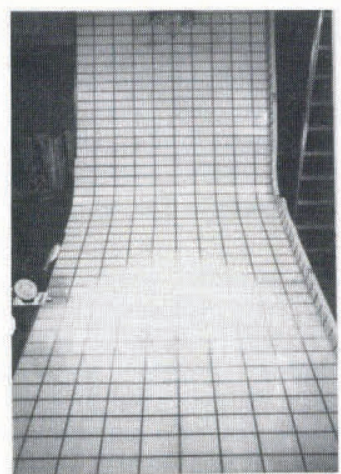

13
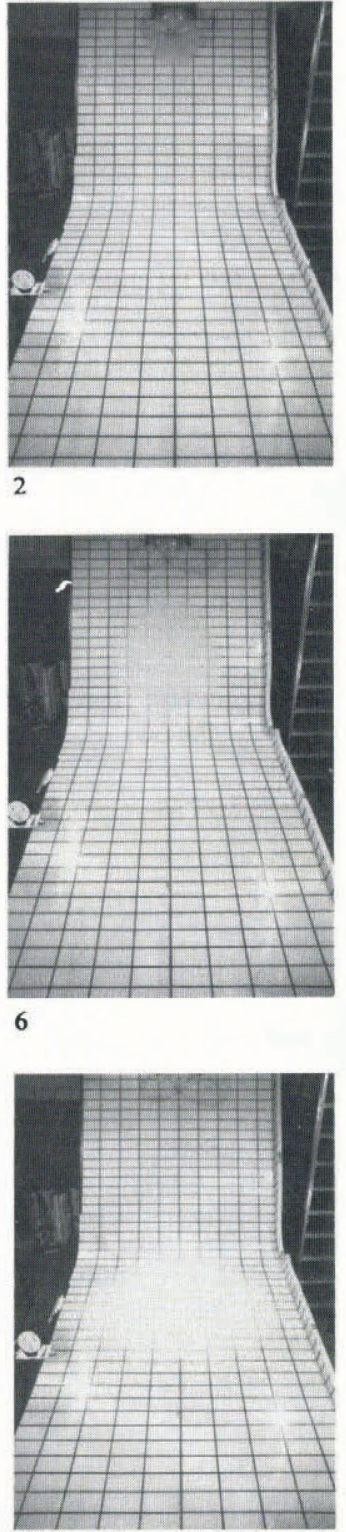

10

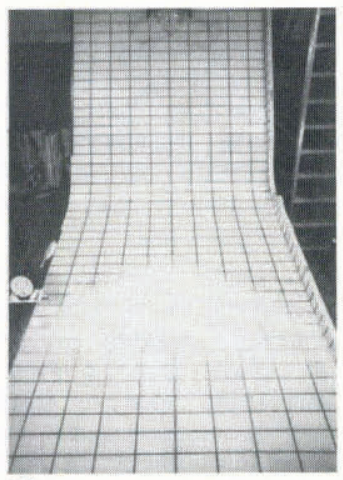

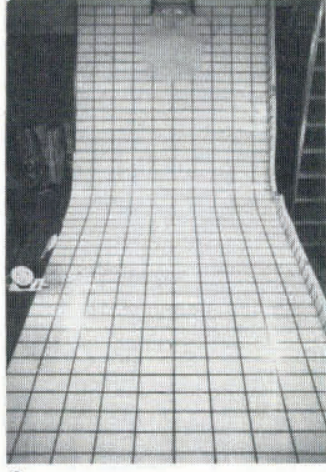

3

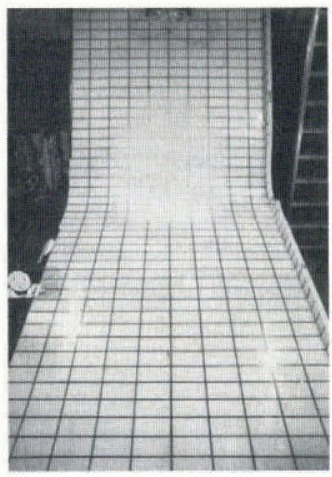

7

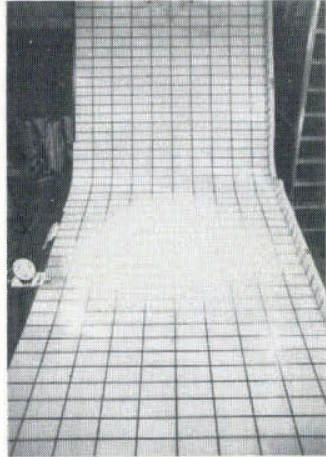

11

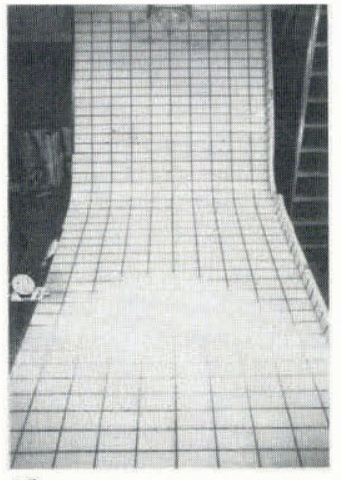

15
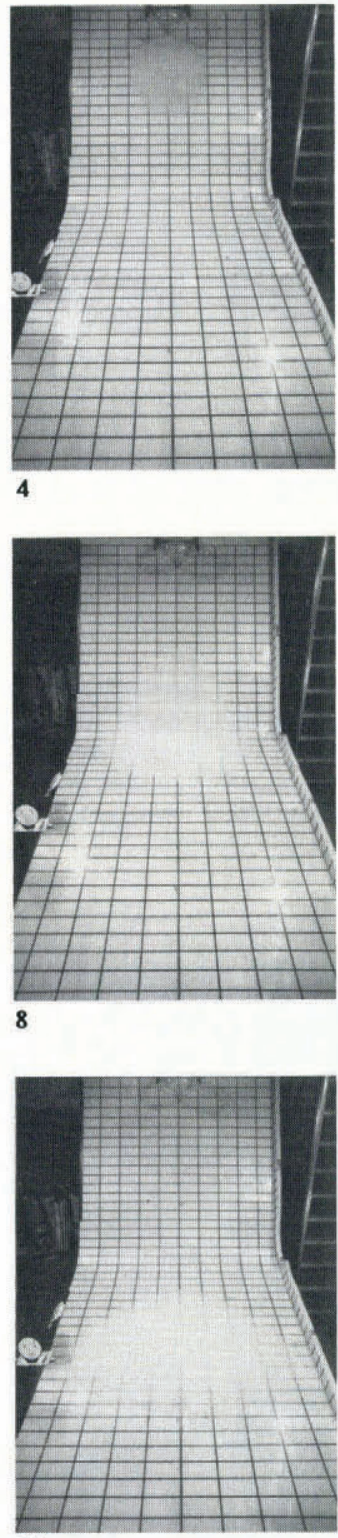

12

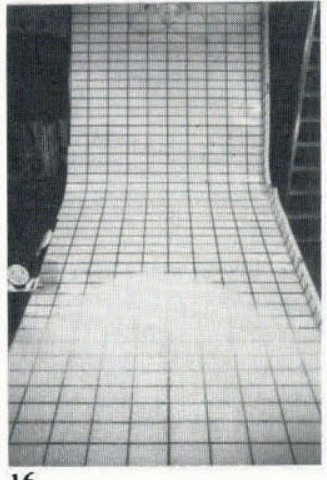

16

Fig. 5.1-16. $5 \mathrm{~mm}$ glass-bead avalanche (No. DA 022). Initiation zone $=45^{\circ}$, total mass $=21.8 \mathrm{~kg}$, frame-to-frame interval $=0.1 \mathrm{~s}$.

and the granules appear to be either in a state of substantial shearing through a non-negligible part of their depth, with the associated dilatation or contraction. Depending on the extent of fluidization, the upper parts of the flow may be in a passive state similar to that in plug flow or the granular mass may be partially or fully fluidized throughout its depth. By assuming the plug-flow condition to be too restrictive, we are led to consider the collisional contribution to stress (Savage, 1979; Savage and Jeffrey, 1981; Jenkins and Savage, 1983; Lun and others, 1984; Jackson, 1986; Norem and others, 1989) in addition to the frictional stress which dominates at high densities and slow deformation rates. The nature of interstitial fluid should also be considered. 


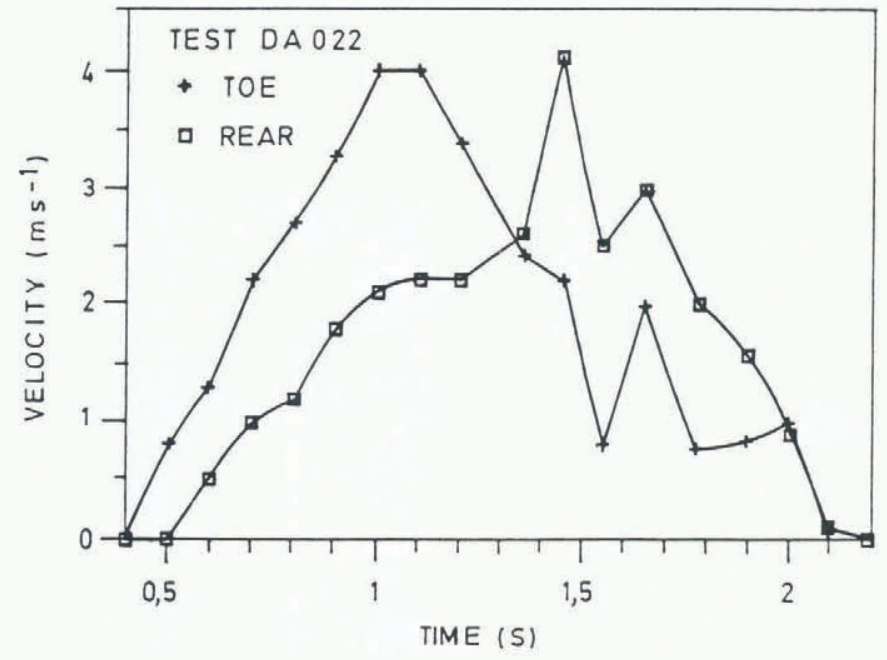

Fig. 6. Approximate velocity against time profile for leading edge and tail of avalanche No. DA $022(5 \mathrm{~mm}$ glass beads, initiation zone $=45^{\circ}$ ); note that time-scale is based on recorded time, not flow time.
This preliminary analysis of the data seems to indicate that maximum velocity is reached as the leading edge enters the transition zone. The granular mass then thickens and contracts as it reaches the curved region, as indicated in Figure 4. Due to this rapid contraction of the medium at the base of the flow, particle-to-particle collisions increase and a highly suspended surface is created at the leading edge (Fig. 3.12a and b). This phenomenon can also be observed in the chute-flow experiments of Hutter and others (1988). It can hardly be interpreted as reflecting an assumption that the "outer flow is passive and rides on a fluidized boundary layer". Here, in the unconfined threedimensional case, it appears that at any given instant in time large gradients exist where different contributions to the stress field dominate, for example, the outer flow can be quite active and random collisional effects are present Any forecasting of final distribution of mass in a run-out zone should not neglect the highly fluidized part of the flow and its tendency to remain in motion after the bulk of the flow material has come to rest. Because natural snow avalanches occur at a high relative frequency, it is also important not to restrict a constitutive relation to non-cohesive materials. By including cohesional, frictional, collisional, and drag contributions to stress, limiting cases can be considered and the model per se is not restricted to a particular material or flow regime.

TABLE II. SUMMARY OF SELECTED PRELIMINARY EXPERIMENTAL RESULTS

\begin{tabular}{|c|c|c|c|c|c|c|c|c|c|c|c|c|c|}
\hline \multirow{2}{*}{\multicolumn{2}{|c|}{$\begin{array}{l}\text { Avalanche } \\
\text { number }\end{array}$}} & $\begin{array}{l}\text { Material- } \\
\text { particle } \\
\text { diameter }\end{array}$ & $\begin{array}{l}\text { Angle of } \\
\text { inclination } \\
\text { in initiation } \\
\text { zone }\end{array}$ & $\begin{array}{l}\text { Surface } \\
\text { type }\end{array}$ & $\begin{array}{l}\text { Total } \\
\text { mass } \\
\text { release }\end{array}$ & $\begin{array}{l}\text { Maximum } \\
\text { velocity } \\
\text { at leading } \\
\text { edge }\end{array}$ & $\begin{array}{l}\text { Time to } \\
\text { maximum at } \\
\text { velocity } \\
\text { leading } \\
\text { edge }\end{array}$ & $\begin{array}{l}\text { Maximum } \\
\text { velocity } \\
\text { at tail }\end{array}$ & $\begin{array}{l}\text { Time to } \\
\text { maximum } \\
\text { velocity } \\
\text { at tail }\end{array}$ & $\begin{array}{l}\text { Maximum } \\
\text { distance } \\
\text { travelled }\end{array}$ & $\begin{array}{l}\text { Time to } \\
\text { maximum } \\
\text { length }\end{array}$ & $\begin{array}{l}\text { Total } \\
\text { elap- } \\
\text { sed } \\
\text { time }\end{array}$ & $\begin{array}{l}\text { Final } \\
\text { length }+\end{array}$ \\
\hline & & $\mathrm{mm}$ & - & & $\mathrm{kg}$ & $\mathrm{m} \mathrm{s}^{-1}$ & $s$ & $\mathrm{~ms}^{-1}$ & $\mathrm{~s}$ & $\mathrm{~m}$ & $s$ & $\mathrm{~s}$ & $\mathrm{~m}$ \\
\hline DA & 018 & $\begin{array}{l}\text { glass beads } \\
3\end{array}$ & 45 & $\begin{array}{l}\text { Makra- } \\
\text { lon }\end{array}$ & 23.4 & 3.1 & 0.95 & 3.5 & 1.3 & 1.47 & 0.8 & 1.45 & 0.85 \\
\hline DA & 019 & $\begin{array}{l}\text { glass beads } \\
3\end{array}$ & 55 & $\begin{array}{l}\text { Makra- } \\
\text { lon }\end{array}$ & 23.6 & 3.8 & 0.8 & 4.5 & 1.0 & 1.18 & 0.7 & 1.4 & 0.90 \\
\hline DA & $022^{*}$ & $\begin{array}{l}\text { glass beads } \\
5\end{array}$ & 45 & $\begin{array}{l}\text { Makra- } \\
\text { lon }\end{array}$ & 21.8 & 4.0 & 0.7 & 4.1 & 1.0 & 1.44 & 0.8 & 1.7 & 0.70 \\
\hline DA & 025 & $\begin{array}{c}\text { quartz } \\
2-3\end{array}$ & 45 & $\begin{array}{l}\text { Makra- } \\
\text { lon }\end{array}$ & 20.0 & 3.5 & 1.0 & 3.8 & 1.15 & 1.39 & 0.9 & 1.6 & 0.75 \\
\hline DA & 027 & $\begin{array}{c}\text { quartz } \\
2-3\end{array}$ & 55 & $\begin{array}{l}\text { Makra- } \\
\text { lon }\end{array}$ & 20.0 & 5.5 & 0.7 & 3.2 & 0.9 & 0.96 & 0.6 & 1.5 & 1.18 \\
\hline DA & 029 & $\begin{array}{l}\text { quartz } \\
2-3\end{array}$ & 35 & $\begin{array}{l}\text { Makra- } \\
\text { lon }\end{array}$ & 20.0 & 3.6 & 0.8 & 3.2 & 1.3 & 1.70 & 1.0 & 1.7 & 0.68 \\
\hline DA & $032^{*}$ & $\begin{array}{c}\text { quartz } \\
5\end{array}$ & 45 & $\begin{array}{l}\text { Makra- } \\
\text { lon }\end{array}$ & 20.5 & 4.0 & 0.8 & 4.0 & 1.1 & 1.29 & 0.8 & 1.8 & 0.75 \\
\hline DA & 033 & $\begin{array}{c}\text { marmor } \\
2-3\end{array}$ & 45 & $\begin{array}{l}\text { Makra- } \\
\text { lon }\end{array}$ & 18.4 & 3.9 & 0.75 & 3.4 & 1.3 & 1.35 & 1.1 & 1.6 & 0.87 \\
\hline DA & $037^{*}$ & $\begin{array}{c}\text { marmor } \\
2-3\end{array}$ & 35 & $\begin{array}{l}\text { Makra- } \\
\text { lon }\end{array}$ & 18.6 & 2.5 & 0.7 & 2.5 & 1.9 & 2.39 & 1.3 & 2.3 & 0.87 \\
\hline DA & 038 & $\begin{array}{c}\text { marmor } \\
5\end{array}$ & 45 & $\begin{array}{l}\text { Makra- } \\
\text { lon }\end{array}$ & 19.0 & 3.8 & 0.6 & 3.8 & 1.25 & 1.45 & 0.9 & 1.6 & 0.88 \\
\hline DA & 041 & $\begin{array}{l}\text { glass beads } \\
5\end{array}$ & 45 & $\begin{array}{l}\text { No. } 120 \\
\text { sand- } \\
\text { paper }\end{array}$ & 21.8 & 4.4 & 0.7 & 6.0 & 0.95 & 1.30 & 0.8 & 1.3 & 1.00 \\
\hline DA & 043 & $\begin{array}{l}\text { glass beads } \\
3\end{array}$ & 55 & $\begin{array}{l}\text { No. } 120 \\
\text { sand- } \\
\text { paper }\end{array}$ & 23.1 & 7.0 & 0.6 & 5.6 & 0.9 & 1.55 & 0.7 & 1.5 & 1.03 \\
\hline DA & 044 & $\begin{array}{l}\text { glass beads } \\
3\end{array}$ & 45 & $\begin{array}{l}\text { No. } 120 \\
\text { sand- } \\
\text { paper }\end{array}$ & 23.1 & 7.5 & 0.6 & 5.0 & 1.0 & 1.50 & 0.95 & 1.7 & 0.90 \\
\hline DA & 049 & $\begin{array}{c}\text { marmor } \\
2-3\end{array}$ & 45 & $\begin{array}{l}\text { No. } 120 \\
\text { sand- } \\
\text { paper }\end{array}$ & 18.4 & 3.7 & 0.8 & 3.1 & 1.0 & 1.93 & 0.8 & 1.5 & 0.64 \\
\hline DA & $051^{*}$ & $\underset{5}{\text { marmor }}$ & 55 & $\begin{array}{l}\text { No. } 120 \\
\text { sand- } \\
\text { paper }\end{array}$ & 18.6 & 3.0 & 0.8 & 3.3 & 1.6 & 2.09 & 1.1 & 1.9 & 0.63 \\
\hline
\end{tabular}




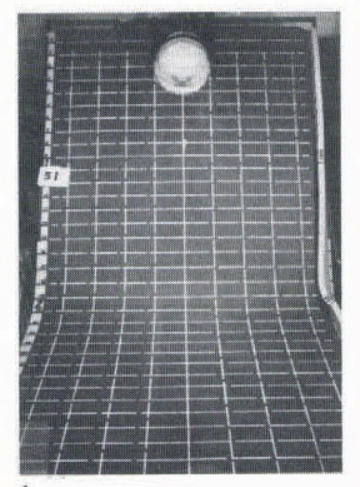

1

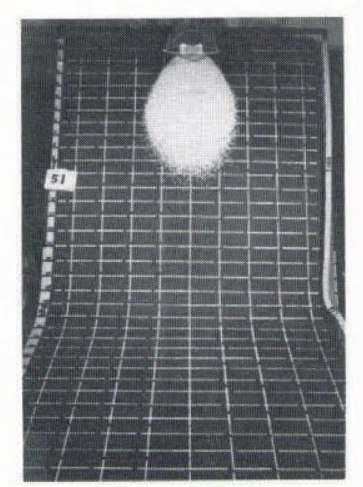

5

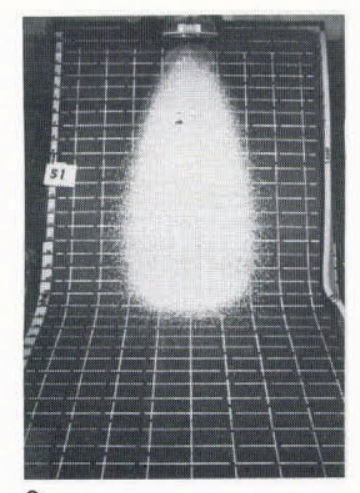

9

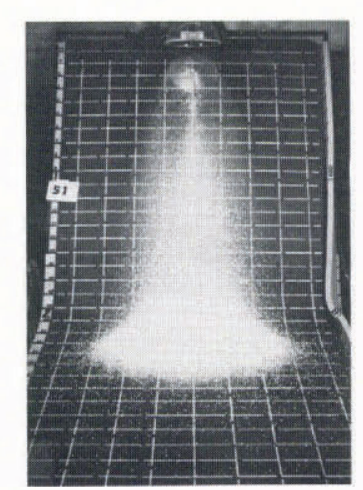

13

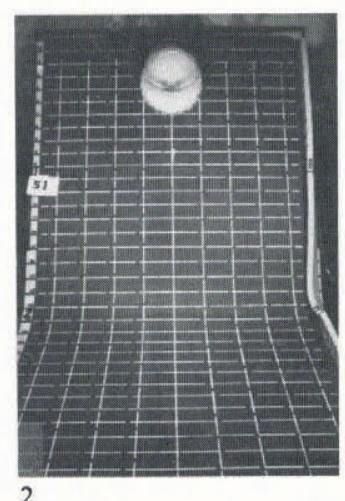

2

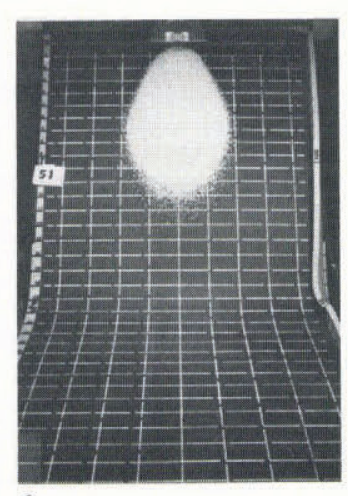

6
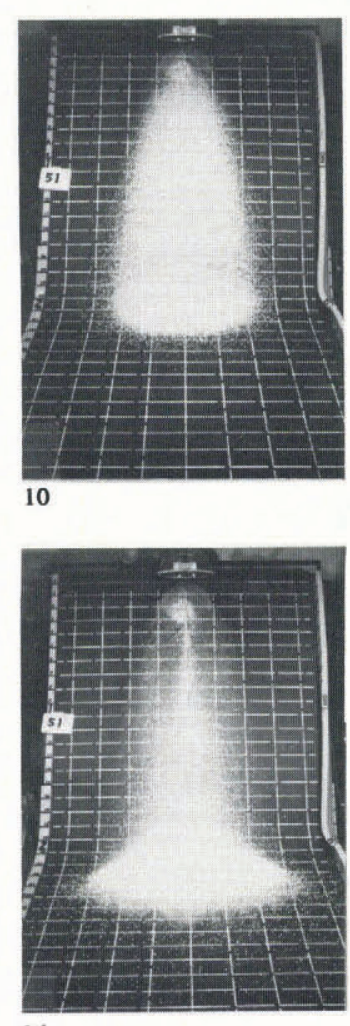

14

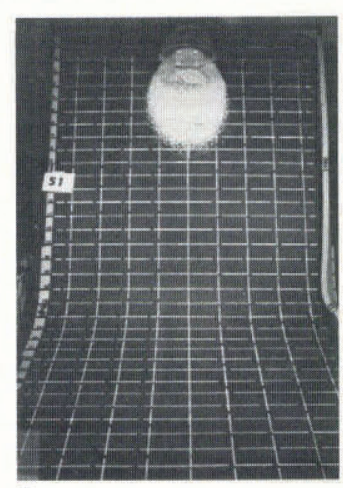

3

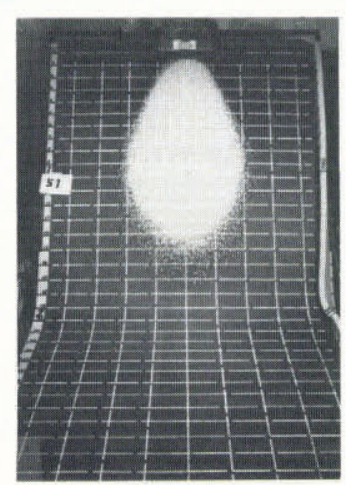

7
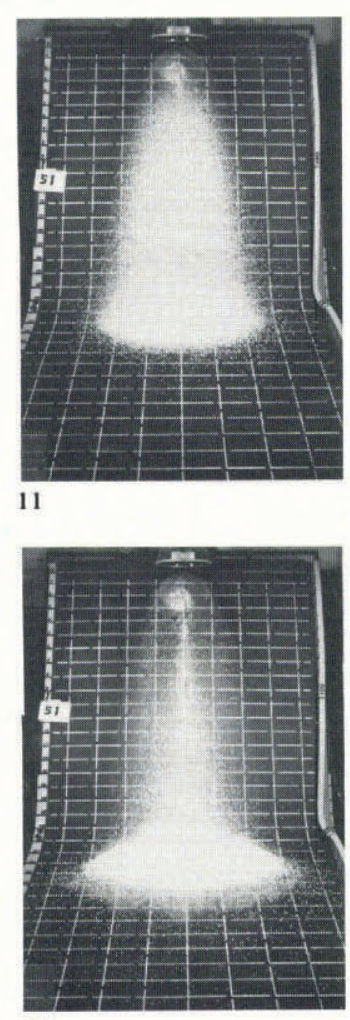

15

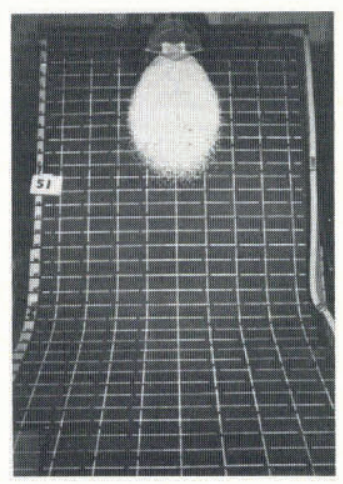

4
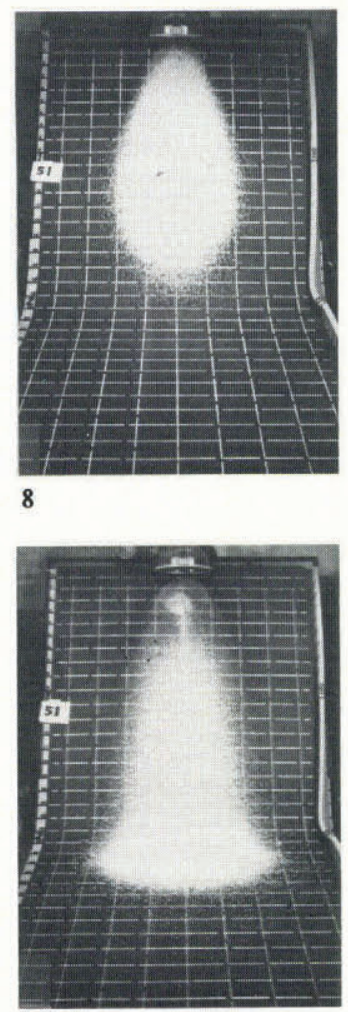

12

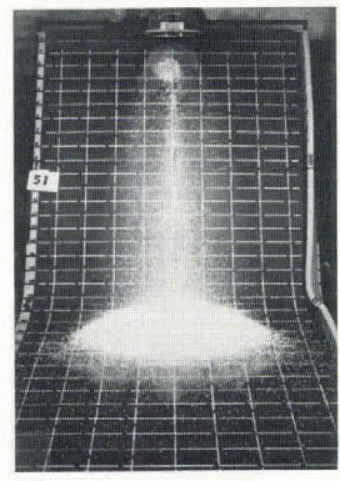

16

Fig. 7.1-16. $5 \mathrm{~mm}$ marmor chips (avalanche No. DA 051) released at $45^{\circ}$ on sandpaper surface, total mass $=18.6 \mathrm{~kg}$, frame-to-frame interval $=0.1 \mathrm{~s}$. 


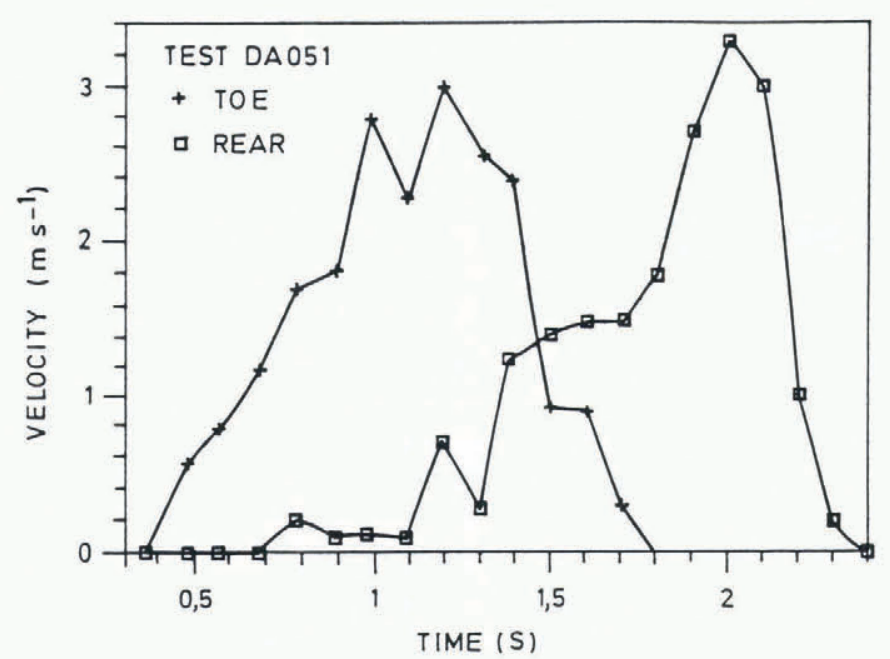

Fig. 8. Approximate velocity against time profile for leading edge and tail of avalanche No. 051. $5 \mathrm{~mm}$ marmor, initiation zone $=45^{\circ}$, sandpaper surface; note that timescale is based on recorded time, not flow time.

\section{FUTURE WORK}

The photographic data resulting from these preliminary experiments will be digitized by a scanning device in order to generate shape functions, velocities, and accelerations with time. Our experiments will be repeated using stereoscopic photography in order to determine the threedimensional evolution of shape and volume through time. It is hoped that by the continuation of this experimental work it will become possible to improve upon and to amend existing theory. Numerical solutions will eventually be sought.

\section{ACKNOWLEDGEMENTS}

We express our thanks to the staff in the laboratory and machine shop of the Institut für Mechanik at the Technische Hochschule Darmstadt. A special note of thanks goes to $H$. Wall, whose personal efforts solved many problems.

\section{REFERENCES}

Gubler, H. 1987. Measurements and modelling of snow avalanche speeds. International Association of Hydrological Sciences Publication 162 (Symposium at Davos 1986 Avalanche Formation, Movement and Effects), 405-420.

Hutter, K., C. Plüss, and N. Maeno. 1988. Some

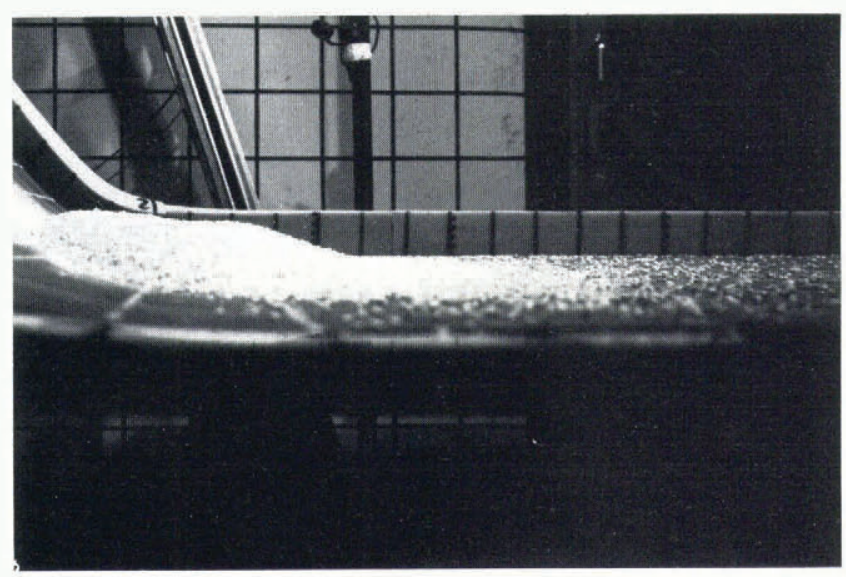

Fig. 9. Final deposition of avalanche (No. DA 051) - side view.

implications deduced from laboratory experiments on granular avalanches. Eidg. Tech. Hochschule, Zürich. Versuchsanst. Wasserbau, Hydrol. Glaziol. Mitt., 94, 323-344.

Hutter, K., S.B. Savage, and Y. Nohguchi. 1989. Numerical, analytical, and laboratory experimental studies of granular avalanche flows. Ann. Glaciol., 13, 109-116.

Jackson, R. 1986. The flow of granular materials and aerated granular materials. In Advances in multiphase flow and related problems. Proceedings, SIAM, 81-100.

Jenkins, J.T. and S.B. Savage. 1983. A theory for the rapid flow of identical, smooth, nearly elastic spherical particles. J. Fluid Mech., 13C, 187-202.

Lun, C.K.K., S.B. Savage, D.J. Jeffrey, and N. Chepurniy. 1984. Kinetic theories for granular flow: inelastic particles in couette flow and slightly inelastic particles in a general flow field. J. Fluid Mech., 140, 223-256.

Melosh, J. 1986. The physics of very large landslides. Acta Mech., 64, 89-99.

Norem, H., F. Irgens, and B. Schieldrop. 1989. Simulation of snow-avalanche flow in run-out zones. Ann. Glaciol., $13,218-225$.

Savage, S.B. 1979. Gravity flow of cohesionless granular materials in chutes and channels. J. Fluid Mech., 92, 53-96.

Savage, S.B. and K. Hutter. 1989. The motion of a finite mass of granular material down a rough incline. $J$. Fluid Mech., 199, 177-215.

Savage, S.B. and D.J. Jeffrey. 1981. The stress tensor in a granular flow at high shear rates. J. Fluid Mech., 110, 255-272. 